\title{
INTERVENÇÕES NO AMBIENTE ESCOLAR UTILIZANDO A PROMOÇÃO DA SAÚDE COMO FERRAMENTA PARA A MELHORIA DO ENSINO
}

\author{
Phillip Vilanova Ilha ${ }^{1 *}$ \\ Ana Paula Santos de Lima ${ }^{* *}$ \\ Daniela Sastre Rossi ${ }^{* * *}$ \\ Félix Alexandre Antunes Soares ${ }^{* * * *}$
}

RESUMO: O presente estudo avaliou o impacto de intervenções colaborativas noambiente escolar e, com esse intuito, utilizou o tema da promoção da saúde como forma de melhoria do ensino. Para tanto, empregou-se a pesquisa-ação colaborativa como principal aporte metodológico. As análises dos dados evidenciaram que as intervenções colaborativas desenvolveram mais mudanças cognitivas e motivacionais do que na prática docente. Encontraram-se indícios de que os professores têm dificuldades em modificar suas práticas docentes, por ainda não estarem preparados para experimentar uma mudança mais profunda e com segurança, bem como por estarem muito atrelados às rotinas pedagógicas exigidas pelo sistema de ensino. No entanto, o estudo revelou modificações nos conceitos e concepções, aos quais novos saberes foram incorporados, ressignificados e desmistificados.

Palavras-chave: Promoção da Saúde. Pesquisa-Ação Colaborativa. Ensino.

\section{INTERVENTION AT SCHOOL ENVIRONMENT USING HEALTH CARE PROMOTION AS A TOOL TO IMPROVE TEACHING}

ABSTRACT: The present study evaluates the impact of collaborative interventions at school environment by using the theme of promoting health care as a means of improving teaching. For that, a collaborative action research was employed as the main methodological framework. Data analysis showed that collaborative interventions developed more cognitive and motivational changes than in teaching practices. We find evidences that teachers have difficulties in modifying their teaching practices for not being prepared to experience a deeper and safely change and for being too tied to pedagogical routines required by the education system. However, the research found changes in concepts and ideas to witch new knowledge was incorporated reassigned and demystified.

Keywords: Promotion of Health Care, Collaborative- Action Research. Teaching.

\footnotetext{
* Doutorando em Educação em Ciências: Química da Vida e Saúde pela Universidade Federal de Santa Maria (UFSM). E-mail: phillip_ilha@hotmail. com

** Doutoranda em Educação e Ensino de Ciências pela Universidade Federal do Rio Grande do Sul (UFRGS). E-mail: ana_paula.sm@ hotmail.com

*** Doutoranda em Educação em Ciências: Química da Vida

e Saúde pela Universidade Federal de Santa Maria (UFSM) E-mail: danisrossi@gmail.com

**** Doutor em Ciências

Biológicas pela Universidade Federal do Rio Grande do Sul (UFRGS). Professor adjunto do Centro de Ciências Naturais e Exatas da Universidade Federal de Santa Maria (UFSM). E-mail: felix@ufsm.br
} 


\section{INTRODUÇÃO}

A promoção da saúde desenvolvida no ambiente escolar é compreendida como combinação de apoios educacionais e ambientais que visam atingir ações e condições de vida conducentes à saúde e que envolvem a formação de atitudes e valores que levam o escolar ao comportamento autônomo, revertendo em benefício à sua saúde e à daqueles que estão à sua volta (ASSIS et al., 2010). Temas atinentes à promoção da saúde não deveriam se limitar apenas a dar conhecimentos. Precisam motivar o aprendizado, estimular o aluno a analisar e avaliar as fontes de informação e, com isso, torná-lo capaz de adotar práticas comportamentais com base no conhecimento.

Nesse sentido, a escola constitui-se em um espaço privilegiado para influenciar e orientar as atitudes e os valores no sentido positivo da vida, ao longo de toda a escolaridade do aluno, para uma melhor qualidade de vida. Apreender comportamentos promotores da saúde na escola requer que os alunos não só adquiram conhecimentos como também estabeleçam competências que lhes permitam pôr em prática aquilo que aprenderam (PEREIRA et al., 2000). Com o intuito de promover tais competências, é preciso desenvolver programas que levem em consideração a potencialidade do aluno e a participação da família e de uma equipe multidisciplinar integrada.

Entretanto, a abordagem de temas relacionados à saúde no âmbito escolar enfrenta problemas específicos, estes são pautados na necessidade de superação dos modelos tradicionais de ensino, que priorizam a transmissão de conteúdos de forma acrítica, sem evidenciar as dúvidas ou contradições que contribuem para o avanço do conhecimento (RAMOS; STRUCHINER, 2009). Para que o ensino seja significativo para o aluno, há necessidade de uma abordagem de conteúdos de forma consciente, crítica e histórica. Segundo Cachapuz (2003), o último século deixou um quadro teórico de referências no qual são enfatizados três construtos: construtivismo, reflexão e comunidade. Entretanto, deixou também a dificuldade crônica em articular tal quadro teórico com práticas de formação relevantes para os professores.

Para Nóvoa (2001), a investigação sobre formação contínua necessita de novos rumos, carece alicerçar-se numa reflexão na prática e sobre a prática, através de dinâmicas de investigação-ação e de investigação-formação, valorizando os saberes de que os professores são portadores e intimamente ligados com as práticas educativas. Nessa perspectiva, modelos de formação contínua que privilegiam a dimensão interativa/reflexiva podem oferecer melhores oportunidades de envolver os professores na sua própria formação. O desenvolvimento desses modelos de formação envolve, necessariamente, novas cumplicidades entre a comunidade de investigadores/formadores e a comunidade de professores (CACHAPUZ, 2003).

Sob essas orientações, a pesquisa colaborativa configura-se como uma metodologia investigativa privilegiada no desenvolvimento de processos formativos que envolvem interpretar e ressignificar a prática docente, dessa 
maneira, buscando favorecer a práxis criativa. No contexto educacional, esse tipo de investigação não busca apenas gerar nova teoria e conhecimento, mas também contemplar problemas imediatos do dia a dia da prática escolar. Trata-se de interpretar e compreender determinada realidade com vistas a intervir nesta e transformá-la. Um aspecto que diferencia a pesquisa colaborativa de outros tipos de pesquisa-ação é que, nesta, a intervenção não é concebida no âmbito acadêmico para ser implementada pelos professores nas escolas, mas planejada em conjunto, por todos os envolvidos. Dessa forma, a investigação é realizada por pesquisadores acadêmicos e profissionais de escolas, sendo que ambos são responsáveis pelo processo (GARRIDO et al., 2000; MIZUKAMI, 2003; THIOLLENT, 2011).

Dada a importância do incremento da qualidade quanto ao ensino e desenvolvimento da promoção da saúde na escola, ações fundamentais para a compreensão, reflexão e entendimento dos estudantes e dos diferentes processos que se desenvolvem em seus corpos e no mundo ao seu redor, que o presente estudo buscou analisar o impacto de intervenções colaborativas no ambiente escolar, para tanto, utilizando o tema da promoção da saúde como forma de melhoria do ensino nas mais diversas áreas do conhecimento.

\section{METODOLOGIA}

O presente trabalho apresenta algumas características da pesquisa-ação colaborativa por propor uma intervenção no contexto escolar a fim de transformar as práticas vigentes. Para Zeichner (1998), a pesquisa colaborativa procura transformar a prática curricular, cujo processo é favorecido pela reflexão do professor sobre a própria prática pedagógica que acontece em parceria com o pesquisador.

Este estudo foi realizado em uma escola pública estadual, vinculada à $8^{\mathrm{a}}$ Coordenadoria de Regional de Ensino, localizada no município de Santa Maria/ RS. A amostra contou com 13 professores que assumiram o compromisso de participação espontânea no projeto, os quais são docentes das disciplinas de Geografia, Ensino Religioso, Ciências, Educação Física, Língua Inglesa, Língua Portuguesa, História e Matemática. Os alunos não foram participantes focais desta pesquisa, porém os dados levantados relativos a eles foram utilizados para investigar o contexto no qual as intervenções colaborativas seriam desenvolvidas. Os dados arrolados foram de 175 escolares do $6^{\circ}$ ao $9^{\circ}$ ano do Ensino Fundamental.

Com intuito de conhecer os sujeitos e seus desafios pedagógicos, bem como elaborar, desenvolver e avaliar um plano de intervenção colaborativa, foram utilizados diferentes procedimentos em situações diversas. Para tanto, empregou-se a seguinte sequência metodológica:

\section{Primeiro momento}

O primeiro momento do estudo teve como objetivo caracterizar o contexto no qual as intervenções colaborativas seriam desenvolvidas. Para 
verificar o contexto da promoção da saúde dos alunos, analisaram-se os seguintes condicionantes da promoção da saúde nos escolares: níveis de atividade física habitual, padrões de consumo alimentar, conhecimento sobre nutrição e estado nutricional. Utilizando-se como instrumentos de avaliação e padrões de referências os seguintes instrumentos: Questionário Internacional de Atividade Física (Ipaq - Versão Curta), Questionário para Avaliação do Conhecimento Nutricional e Consumo Alimentar proposto por Bertin et al. (2010), Relação Índice de Massa Corporal para Idade (IMC/Idade), proposta pela Organização Mundial da Saúde de 2007 e com os pontos de cortes propostos pelo Sistema Nacional de Alimentação e Nutrição (Sisvan, 2009).

Para verificar o contexto da prática docente, empregou-se uma entrevista semiestruturada aos professores, constituída de questões sobre os recursos metodológicos utilizados para o desenvolvimento de temas relacionados à promoção da saúde. A análise dos dados foi fundamentada na análise categorial, com desmembramento das transcrições das entrevistas em categorias, constituída por temas que emergiam do texto. As entrevistas passaram por um crivo de classificação e de quantificação, segundo a frequência de presença ou ausência de itens de sentido (BARDIN, 2011).

\section{Segundo momento}

O segundo momento do estudo consistiu no programa de intervenção colaborativa, que visou à transformação das práticas vigentes dos professores por meio da formação crítica e reflexiva sobre as práticas pedagógicas. As intervenções foram elaboradas, juntamente com os gestores e professores participantes, durante o transcorrer da pesquisa, levando em conta as análises e reflexões do primeiro momento do estudo. As intervenções colaborativas foram assim estruturadas:

\section{$1^{a}$ Intervenção: Análises e reflexões do contexto}

Iniciou-se o programa de intervenção propriamente dito com o que Ibiapina (2008) denomina de conversa reflexiva. E levou em conta a importância da reflexão do professor; e, dessa maneira, propiciaram-se momentos de reflexões a partir das análises e discussões dos resultados do primeiro momento do estudo. A primeira intervenção consistiu na conversa reflexiva sobre o contexto da promoção da saúde dos alunos e o contexto da prática docente. Tais conversas reflexivas ocorreram durante dois encontros semanais, em horários destinados à hora-atividade.

\section{$2^{a}$ e $3^{a}$ Intervenções: Ciclo de estudos}

A segunda e a terceira intervenção colaborativa compuseram-se de momentos de aprofundamento teórico com os professores e pesquisador. A proposta do estudo teórico foi cogitada no final da primeira intervenção colaborativa, haja vista ser esse um dos objetivos da modalidade de pesquisa colaborativa: formação e pesquisa (IBIAPINA, 2008). 
Nasegundaintervenção foram trabalhados temas sobresaúde epromoçãoda saúde, apoiados em alguns recortes de trabalhos dos autores: Andrade (1995), Pereira et al. (2000), Sícoli e Nascimento (2003), Triches e Giugliani (2005), Brasil (2002) e pesquisas do Instituto Brasileiro de Geografia e Estatística (BRASIL, 2009).

$\mathrm{Na}$ terceira intervenção foram trabalhados temas pertinentes às teorias pedagógicas e estratégias metodológicas de ensino, desse modo, refletindo sobre temas transversais, pedagogia de projetos, pedagogia da problematização e temas geradores, apoiados nos seguintes autores: Araújo (2003), Parâmetros Curriculares Nacionais (BRASIL, 1998), Libâneo (2005), Berbel e Gamboa (2011) e Freire (2011).

A intenção dos ciclos de estudo foi proporcionar um espaço de formação para os professores de modo a ampliar e aprofundar a discussão sobre a temática promoção da saúde e suas aplicações em sala de aula. Esses ciclos ocorreram durante dois encontros semanais, fora dos horários destinados à hora-atividade.

\section{$4^{a}$ Intervenção: Elaboração de projetos pedagógicos}

A quarta intervenção colaborativa deu-se em momentos de formulação de ações que poderiam transformar a realidade ou procurar soluções para os problemas encontrados no contexto dos alunos. Nesse sentido, foi necessário resgatar a realidade do contexto da promoção da saúde dos alunos e os conhecimentos obtidos durante os ciclos de estudo. E, assim, esses dois fatores foram conjugados e relacionados, com isso, buscando-se propostas de transformação das práticas vigentes dos professores por meio da formação reflexiva sobre as suas próprias práticas pedagógicas. Tais intervenções colaborativas ocorreram durante dois encontros semanais, fora dos horários destinados à hora-atividade.

\section{$5^{a}$ Intervenção: Desenvolvimento dos Projetos Pedagógicos}

O objetivo da quinta intervenção pedagógica foi o de acompanhar o processo de desenvolvimento dos projetos pedagógicos desenvolvidos pelos professores, bem como colaborar com o seu desenvolvimento. A colaboração deu-se diretamente com orientações e trocas de informações entre pesquisador e professor, sem interferência nas aulas ou nos projetos propostos. O acompanhamento e também as ações colaborativas desenvolveram-se durante dois meses, em encontros quinzenais com grupos pequenos de professores, em horários destinados à hora-atividade.

Para avaliar o processo das intervenções, utilizou-se o diário de campo e a observação participante. No diário de campo foram registrados os momentos observados, com uma descrição dos sujeitos, espaços, acontecimentos e conversas, bem como as reflexões e ideias dos participantes da pesquisa. Os registros foram realizados em forma de descrição real, ou seja, grafados da maneira como foram ouvidos e observados e da mesma forma como os participantes os expuseram. Já a observação participante revelou-se a partir do registro das observações e interpretações do pesquisador no diário de campo, no tocante aos observados, nessa perspectiva, focalizando suas ideias, reflexões e conversas. 


\section{Terceiro momento}

No terceiro momento do estudo buscou-se verificar as mudanças provocadas pelas intervenções colaborativas, relativamente aos professores participantes, no que se refere a contribuições para o saber e à prática docente de cada um. Desse modo, utilizou-se um questionário com duas questões fechadas sobre as intervenções e os saberes adquiridos e duas questões abertas relativas às mudanças das práticas pedagógicas e atividades aplicadas. O questionário foi aplicado, no final do ano letivo, aos professores-participantes das intervenções colaborativas.

\section{ANÁLISE E DISCUSSÃO DOS RESULTADOS}

Os resultados são apresentados e discutidos conforme a sequência metodológica percorrida durante o estudo.

\section{Primeiro momento do estudo}

Como os escolares não foram participantes focais da presente pesquisa, os dados levantados relativos a eles são apresentados apenas com o objetivo de caracterizar o contexto da promoção da saúde no ambiente escolar, não havendo maior discussão sobre eles.

A partir dos resultados, quanto ao estado nutricional, observou-se que pouco mais da metade $(56,7 \%)$ dos escolares apresenta peso normal (eutrofia) em relação à sua estatura, idade e sexo e altos índices de peso acima do normal, chegando a 42,8\% da amostra estudada. Percentual esse preocupante quando comparado com índices brasileiros da Pesquisa de Orçamentos Familiares, realizada pelo Instituto Brasileiro de Geografia e Estatística (BRASIL, 2009), com crianças brasileiras, pelo qual se constatou que $21,7 \%$ dos meninos de 10 a 19 anos de idade apresentam excesso de peso; e 19,4\% das meninas da mesma idade estão acima do peso ideal.

Quanto aos hábitos alimentares dos escolares, verificou-se que a maioria foi classificada com hábitos alimentares regulares (77,6\%), dado seguido de maus hábitos alimentares $(18 \%)$ e bons hábitos alimentares (4,4\%). Apesar de a maioria dos escolares possuir hábitos alimentares regulares, os percentuais de hábitos alimentares inadequados são bem superiores quando comparados a achados do estudo de Bertin et al. (2010), que analisou 259 estudantes da rede pública de ensino da cidade de Indaial/SC, com ocorrência de 3,1\% dos escolares com maus hábitos alimentares.

$\mathrm{Na}$ análise dos conhecimentos nutricionais, detectou-se que 85,3\% dos escolares foram classificados com baixo conhecimento nutricional, 14,7\% com conhecimento nutricional moderado e nenhum escolar com alto conhecimento nutricional. O baixo nível de conhecimento nutricional torna-se preocupante na população estudada, pois índices bem melhores foram encontrados em estudos similares. Entre eles, o estudo de Triches e Giugliani (2005), o qual analisou o conhecimento nutricional de 573 crianças das escolas municipais de Dois Irmãos e Morro Reuter, no Rio Grande do Sul, e verificou um percentual de 90,8\% 
de escolares com bons ou regulares conhecimentos nutricionais. Em estudo desenvolvido por Bertin et al. (2010), esses pesquisadores observaram que 93\% dos escolares tinham bons ou ótimos conhecimentos nutricionais.

Em relação ao nível de atividade física habitual, averiguou-se que a maioria dos escolares foi classificada como ativos $(66,5 \%)$ ou muito ativos $(28,1 \%)$, enquanto que 5,4\% foram classificados como irregularmente ativos. Esses índices são superiores aos encontrados pela Pesquisa Nacional da Saúde do Escolar, desenvolvida pelo Instituto Brasileiro de Geografia e Estatística (BRASIL, 2009), que revelou que, para o conjunto das capitais e do Distrito Federal, 43,1\% dos escolares eram ativos.

$\mathrm{Na}$ análise do contexto da prática docente, sobre o tema promoção da saúde, os resultados da entrevista semiestruturada revelaram que $23 \%$ dos professores não trabalham temas relacionados à promoção da saúde em suas aulas, enquanto que $77 \%$ relataram desenvolver algum tema relacionado à temática.

Em relação aos recursos metodológicos utilizados para o desenvolvimento do tema, para melhor análise e discussão dos resultados, as respostas dos professores foram categorizadas e quantificadas, por similaridade, em seis grupos, conforme elenca-se na tabela 1.

Tabela 1: Percentual das respostas dos recursos metodológicos utilizados para trabalhar o tema promoção da saúde.

\begin{tabular}{|c|c|}
\hline Recursos metodológicos & Percentuais \\
\hline Na forma de textos & $70 \%$ \\
\hline Dentro do conteúdo da disciplina & $40 \%$ \\
\hline Através de diálogos & $20 \%$ \\
\hline Através de vídeos & $20 \%$ \\
\hline Na forma de trabalhos escolares & $20 \%$ \\
\hline Através do livro didático & $10 \%$ \\
\hline
\end{tabular}

Como a maioria dos professores respondeu que utiliza mais de uma forma de desenvolver o tema em suas aulas, os percentuais dos grupos de categorias não correspondem a cada resposta do professor, e sim a cada forma de desenvolver o tema promoção da saúde.

Observou-se que o tema promoção da saúde era desenvolvido principalmente por meio de textos e conforme o conteúdo da disciplina; e, em menor percentual, através de diálogos, vídeos, trabalhos escolares e livros didáticos. Percebeu-se, ainda, a partir das respostas dos professores, que as formas de trabalhar o tema promoção da saúde estavam ligadas com o conteúdo desenvolvido pela disciplina, como se pode observar nos seguintes extratos retirados da entrevista: 
“Trabalho o tema promoção da saúde quando trabalho os alimentos e sistema digestório [...] é trabalhado, mais bem focado no conteúdo. É trabalhado principalmente no $7^{\circ}$ ano. Falo sobre o trabalho físico, mais nunca foquei a importância." (Professor A)

"A gente trabalha quando é trabalhado sobre a economia, a questão populacional. Falamos sobre a perspectiva de vida, sexo e obesidade. A gente acaba tocando nesses assuntos. Claro que não aprofundamos tanto como deveríamos [...].” (Professor B)

"Sempre que possível, dou algum texto, um vídeo ou algum filme que fala sobre [...]." (Professor C)

Segundo Mainardi (2010), temas relacionados à saúde, assim como a promoção da saúde, precisam ser trabalhados pelos professores de forma transversal, sem tanto enfoque nos conteúdos, mas contextualmente, no dia a dia, sem preocupação muito grande com informação e mais com a formação de hábitos e atitudes que visem à melhoria efetiva na qualidade de vida dos alunos. Lomônaco (2004) coloca que a melhora da saúde de cada educando deve partir de sua consciência crítica, a qual se daria por meio da educação, por meio de um processo educativo que forneça uma formação integral, assim, o educando teria as ferramentas para poder lutar por um nível adequado de saúde.

Os resultados encontrados no primeiro momento do estudo revelaram que, de maneira geral, o contexto no qual seria desenvolvido o estudo apresentava-se com escolares de elevado nível de obesidade, com hábitos alimentares regulares, grande déficit em termos de conhecimentos nutricionais e ativos fisicamente. Apontaram, também, que a abordagem do tema promoção da saúde, desenvolvido pelos professores, estava centrada no conteúdo da disciplina, por meio do qual não eram efetuadas correlações ou integrações com outras disciplinas, bem como não se buscava sua contextualização.

\section{Segundo momento do estudo}

O segundo momento do estudo consistiu no programa de cinco intervenções colaborativas.

\section{Primeira Intervenção: análise e reflexões do contexto}

Iniciou-se a primeira intervenção através de conversas reflexivas (IBIAPINA, 2008) sobre o contexto da promoção da saúde dos alunos, bem como do contexto do tema promoção da saúde desenvolvido nas aulas. A conversa reflexiva iniciouse com a apresentação dos resultados dos alunos, quando se pôde observar que os professores se surpreenderam com o elevado nível de obesidade, com os hábitos alimentares e com o grande déficit de conhecimento nutricional dos alunos. Isso demonstra que os professores não conheciam a realidade dos próprios alunos.

$\mathrm{Na}$ sequência discutiu-se o contexto da prática docente. Observando-se, através de pequenos relatos e reflexões dos professores, que o tema promoção da saúde era pouco trabalhado e, quando trabalhado, era desenvolvido centrado 
nos conteúdos de cada disciplina e de forma sistemática e descontextualizada. Como retrata a fala de um professor da equipe diretiva: "Os professores trabalham esses temas nas suas aulas, quando trabalham alimentos, atividade física [...], dentro do conteúdo".

Levantou-se, através dos relatos dos professores, registrados no diário de campo, que, apesar de $77 \%$ dos professores terem respondido que trabalhavam temas relacionados à promoção da saúde em suas aulas, isso era desenvolvido em poucos momentos, através de atividades pontuais centradas no conteúdo da disciplina e sem a contextualização do tema.

Os Parâmetros Curriculares Nacionais (BRASIL, 1998) orientam que o tema saúde, bem como a promoção da saúde, precisa ser desenvolvido de forma transversal aos conteúdos da disciplina, sem tanto enfoque nas informações, mas contextualmente, no dia a dia, com orientações na formação de hábitos e atitudes que visem à melhoria efetiva na qualidade de vida dos alunos. Porém, isso só se torna possível se o professor conhecer a realidade do aluno, sua linguagem, seus valores e objetivos de vida, assim, interagindo com conceitos e fatos do dia a dia na estruturação do conteúdo de sua disciplina. Segundo Ribeiro (2010), os professores precisam compreender a sociedade e a política que a integra, pois somente percebendo as transformações das ações social e cultural do meio em que atuam, assim como os níveis social, econômico e cultural de seus alunos, é que se poderá afirmar que ele será capaz de transformar aquela realidade.

Após a conversa reflexiva, o grupo de professores ressaltou a necessidade de realizar ciclos de estudos a respeito dos temas saúde, promoção de saúde e teorias pedagógicas. Tal atividade adveio da necessidade de aprofundamento teórico sobre os temas, por parte dos professores.

\section{Segunda e Terceira Intervenções: ciclos de estudos}

A segunda e a terceira intervenção consistiram em momentos de estudos nos quais se optou por uma exposição dialogada do estudo teórico, o que permitiu interferências dos colaboradores.

$\mathrm{Na}$ segunda intervenção, percebeu-se que os professores se mostraram tímidos e que, pela anotação no diário de campo, apenas um respondeu à questão proposta.

Após algumas explanações teóricas, os professores demonstraram maior disposição em expor suas concepções e vivências. Observou-se que os estudos teóricos realizados descobriam, quase sempre, elementos para a discussão, fazendo virem à tona questões que identificavam mais seus estilos de vida do que suas práticas docentes.

Averiguou-se, através da observação participativa, que os professores participantes revelaram, na sua maioria, um quadro conceitual ingênuo, ainda em elaboração, referente ao tema promoção da saúde. Os docentes apresentaram ideias reduzidas, opiniões contraditórias e alguns conceitos equivocados em relação aos conhecimentos científicos. 
A partir da aproximação da teoria, o ciclo de estudo ganhou novo rumo, as experiências compartilhadas foram aliadas aos momentos de explanação teórica e os saberes foram expostos, incorporados e ressignificados através da reflexão teórica do tema. As filiações teóricas dos professores foram paulatinamente descortinadas, ideias foram reformuladas, conceitos reestruturados, tomadas de posição rediscutidas, o que proporcionou mais amadurecimento conceitual. Apesar de a ação reflexiva ficar mais voltada às narrativas do estilo de vida pessoal e pouco à ação pedagógica, essa se mostrou enriquecedora, pois, como mencionado, saberes foram incorporados, ressignificados e desmistificados.

Segundo Alarcão (2005), a exposição dos conhecimentos prévios instiga, também, o professor a revisitar seus referenciais, a buscar propostas de atuação, por meio do processo reflexivo, com o intuito de evoluir em sua ação pedagógica e apreender novos conhecimentos. Nesse contexto, a reflexão assume importante missão de desvendamento da realidade individual e social do professor. Para que o professor possa ter algum papel no processo de produção de conhecimento nos alunos, esses conhecimentos precisam ser produzidos no professor, ou seja, ele precisa dominar tais conhecimentos para que possa contribuir de alguma forma para que o aluno também chegue a esse domínio. O professor necessita não apenas dominar esses conhecimentos específicos, mas também os processos, as formas através das quais os conhecimentos específicos se produzem no âmbito do trabalho pedagógico que se desenvolve no interior da escola. A competência solicitada aos professores vai além daquela referida aos saberes específicos das áreas do conhecimento, a estes é necessário somarem-se o conhecimento e a capacidade de lidar com o aluno, de trabalhar a informação que chega à sala de aula por vias diversas, de responder às expectativas inerentes a uma nova abordagem do currículo, tanto no que diz respeito à seleção e ao tratamento conceitual e integrador de conteúdos quanto ao tratamento metodológico adotado (NÓVOA, 2001).

$\mathrm{Na}$ terceira intervenção, observou-se que, durante as ações reflexivas, os professores revelaram conhecimento teórico sobre os assuntos abordados e quase todos demonstraram que, de uma forma ou de outra, conheciam as abordagens. Percebeu-se, assim, que esses professores têm conhecimento sobre "correntes pedagógicas contemporâneas” (LIBÂNEO, 2005). Com essa observação, pode-se destacar que os professores conhecem outras metodologias diferentes das aplicadas por eles, mas não desenvolvem. As principais dificuldades ou entraves metodológicos, segundo relatos dos professores, residem na estrutura da escola ou no próprio sistema de ensino, como se denota das colocações dos professores:

"Não tem como aplicar essas metodologias porque o espaço físico da escola não permite [...]. Não é que a gente não queira, o espaço físico é inadequado." (Professor D)

"Aqui na escola a gente até tenta, mais pela falta de possibilidade, tempo para se reunir e montar um trabalho mais amplo que consiga pegar mais disciplinas para trabalhar em projetos fica muito difícil.” (Professor E) 
Segundo Moran (2006), no Brasil, há uma preocupação com o ensino de qualidade mais do que com a educação de qualidade. De acordo com o autor, para haver uma educação de qualidade, há a necessidade de uma infraestrutura adequada e atualizada, além de professores preparados, bem-remunerados, motivados e com boas condições profissionais.

Mas a falta de infraestrutura e de tempo para planejamento não é o único entrave, pois, como coloca Libâneo (2005), mesmo quando sistemas de ensino tornam oficiais teorias pedagógicas, no interior das salas de aulas, as atitudes pedagógicas e as metodologias se mantêm intocáveis. O que leva a afirmar, segundo o autor, que a produção editorial, os cursos de aperfeiçoamento e os sistemas de ensino, quando muito, introduzem, na prática dos professores, algumas mudanças curriculares, novas habilidades ou uma nova técnica, sem afetar o núcleo forte das tendências pedagógicas mais impregnadas na prática dos professores.

Porém, constata-se o aparecimento de novas teorias e correntes, as quais não desenvolveram suficiente base pedagógico-didática para ajudar os professores em suas decisões e ações cotidianas e que não procedem no mundo prático, no contexto atual da escola, mas somente no mundo acadêmico (LIBÂNEO, 2005).

\section{Quarta Intervenção: elaboração de projetos pedagógicos}

Após a recapitulação do contexto dos alunos e reflexões dos ciclos de estudo, os professores foram desafiados a elaborar ações pedagógicas viáveis, coerentes e que estivessem associadas ao tema promoção da saúde e, principalmente, que propiciassem retorno à realidade encontrada no contexto dos alunos. Ressaltou-se a importância de que todas as ações propostas fossem aplicadas, pois, além de poder contribuir com a realidade estudada, isso concretizaria o movimento final da prática reflexiva.

Segundo Freire (2011), a prática reflexiva é a orientação fundamental para a formação continuada de professores, pois, a partir desse princípio, abandona-se o conceito de formação docente como processo de atualização que se dá através da aquisição de informações científicas, didáticas e psicopedagógicas descontextualizadas da prática educativa do professor, para adotar um conceito de formação que consista em construir conhecimentos e teorias sobre a prática docente.

Observou-se que, inicialmente, os professores reuniram-se em pequenos grupos que realizaram momentos de reflexão e planejamento. A partir dessa ação reflexiva, surgiram as seguintes sugestões de projetos: "Atividade Física e Lazer", proposto pelos professores de Educação Física e Língua Portuguesa; "Países, Comidas, Consumo e a Cultura", proposto pelos professores de Língua Portuguesa, Geografia e História; “Alimentação Saudável e Qualidade de Vida”, proposto pelos professores de Ciências e Matemática.

Depois, cada grupo socializou as sugestões dos projetos. Momento esse marcado por reflexões e questionamentos do "como fazer" dentro do atual contexto da escola. 
Na sequência, a partir dos questionamentos e das ações reflexivas, surgiram algumas premissas para o desenvolvimento dos projetos, foram elas: o projeto poderia partir dos conhecimentos, questionamentos ou curiosidade dos alunos; teria de levar o aluno a pesquisar novos conhecimentos ou conceitos; os temas precisariam estar ligados ao contexto do aluno e da escola; e o professor teria o papel de mediador da aprendizagem.

Essas premissas vêm ao encontro das ideias de Prado (2003), o qual coloca que os projetos pedagógicos devem permitir que o aluno aprenda-fazendo e reconheça a própria autoria naquilo que produz por meio de questões de investigação que o impulsionam a contextualizar conceitos já conhecidos e descobrir outros que emergem durante o desenvolvimento do projeto, momento em que o professor desempenha o papel de mediação, pois, ao mesmo tempo em que o aluno precisa reconhecer a sua própria autoria no projeto, ele também precisa sentir a presença do professor que ouve, questiona e orienta, dessa maneira, visando propiciar a construção de conhecimento do aluno (PRADO, 2003).

Ao final da intervenção, observou-se que ainda estava em questionamento o "como fazer" o projeto pedagógico dentro da atual estrutura do sistema de ensino, a qual, segundo relatos dos professores, dificulta o desenvolvimento de projetos que envolvam ações interdisciplinares e impliquem aprendizagens que extrapolem o tempo da aula e o espaço físico da sala de aula e da escola. Assim, utilizando a referência de Araújo (2003), o grupo de professores optou por trabalhar os conteúdos das disciplinas como eixo condutor do processo educativo e a inserção dos projetos pedagógicos de maneira transversal.

\section{Quinta Intervenção: desenvolvimento dos projetos pedagógicos}

Após a elaboração, os professores aplicaram, durante dois meses, os projetos pedagógicos. Nesse processo observou-se que determinados professores encontraram algumas dificuldades, as quais foram configuradas como fragilidades para a execução dos projetos como planejados, sendo elas:

Os conteúdos curriculares previstos no trimestre não foram abordados pelo projeto. Uma questão que gerou questionamento e dificuldade no processo de desenvolvimento do projeto, por parte de alguns professores, foi o fato de que nem todos os conteúdos curriculares previstos para serem estudados naquele trimestre eram passíveis de serem abordados no contexto do projeto.

A necessidade de "quantificar os alunos". O período de aplicação do projeto deu-se no final do ano letivo, momento em que há um grande número de avaliações com o objetivo de quantificar o conhecimento adquirido pelo aluno durante o ano, por meio de notas e conceitos.

Pouco tempo destinado ao projeto. Com a preocupação do desenvolvimento dos conteúdos curriculares previstos no trimestre e também com as aplicações das avaliações, não houve tempo para a aplicação do projeto.

Nesse ínterim, apenas o projeto "Atividade Física e Lazer" foi desenvolvido como planejado na quarta intervenção, envolvendo 31 alunos de uma turma 
do $7^{\circ}$ ano. Com base nos relatos, falas, fotos e relatório dos professores, constatou-se que o desenvolvimento do projeto "Atividade Física e Lazer" seguiu o seguinte procedimento:

O tema "Atividade Física e Lazer" foi a atividade geradora e apresentou a ideia principal do projeto. Os professores procuraram trabalhar com um tema em comum e, a partir dele, planejar e vivenciar atividades interdisciplinares que mostrassem a importância da promoção da saúde para os alunos.

Nas atividades pedagógicas, inicialmente, os professores verificaram quais eram as curiosidades dos alunos sobre o tema e, após algumas perguntas e discussões, formulou-se o questionamento principal e norteador do projeto: Quais são as atividades físicas e de lazer praticadas pela nossa comunidade?

A partir do questionamento norteador, os alunos refletiram sobre a necessidade da construção de um questionário para aplicação na comunidade. Mas, para tal, precisar-se-ia de conhecimentos mínimos sobre o tema. Assim, durante as aulas de Educação Física e Língua Portuguesa, os professores trabalharam conteúdos das suas disciplinas relacionados ao tema, e pesquisas foram realizadas na sala de informática.

Após estudos e pesquisas sobre o tema, os alunos, em pequenos grupos, formularam questões para a confecção do questionário. E, para selecionar as questões que iriam compor o questionário, houve um debate e votação das questões mais relevantes.

Devido ao término do ano letivo, a culminância do projeto deu-se pela confecção do questionário.

Através da análise dos procedimentos metodológicos do projeto desenvolvido, identificou-se que os professores utilizaram como principal aporte teórico a estratégia de projetos de Araújo (2003). Na estratégia de projetos, o aluno aprende no processo de produzir, de levantar dúvidas, de pesquisar e de criar relações que incentivem novas buscas, descobertas, compreensões e reconstruções de conhecimento (PRADO, 2003). E, portanto, o papel do professor deixa de ser aquele que ensina por meio de transmissão de informações, para criar situações de aprendizagem, assim, cabendo ao professor realizar as mediações necessárias para que o aluno possa encontrar sentido naquilo que está aprendendo a partir das relações criadas nessas situações.

Os demais projetos, "Países, Comidas, Consumo e a Cultura" e "Alimentação Saudável e Qualidade de Vida", não foram desenvolvidos de forma interdisciplinar e como planejados na quarta intervenção. Os desenvolvimentos dos projetos ficaram restritos às disciplinas, foram trabalhados dentro do conteúdo ou em forma de debates, em que o professor elencava temas relacionados ao projeto e ao contexto dos escolares e, dessa forma, desenvolveram-se reflexões e debates entre a turma.

A partir das observações e análises da quinta intervenção, constatouse que os professores percebem a necessidade de mudar suas práticas docentes, mas não sabem bem como fazer e não estavam preparados para experimentar 
uma mudança significativa com segurança, pois um dos desafios da aplicação dos projetos pedagógicos é a dificuldade de gerir o tempo e de ater-se por muito tempo para atingir os objetivos educativos. Outro inconveniente está associado à dificuldade de o professor, em tempo útil, conseguir "orquestrar" os ritmos de trabalho diferenciados dos alunos e de, nem sempre, ter a possibilidade de corrigir os percursos de aprendizagem de cada aluno. Aliadas a isso, somam-se as exigências do sistema de ensino de cumprir o planejamento, entregar notas, cadernos, entre outras.

\section{Terceiro momento do estudo}

No terceiro momento do estudo buscou-se verificar as mudanças provocadas pelas intervenções colaborativas. Detectou-se que, através da análise da primeira questão do questionário, avaliação das intervenções, 54\% dos professores avaliaram como "muito bom" as intervenções colaborativas; 38\%, como "bom"; e $8 \%$, como regular.

No tocante à segunda questão, contribuição das intervenções para a aquisição de conhecimento sobre o tema, observou-se que 77\% responderam que as intervenções colaborativas contribuíram muito; e 23\% responderam que contribuíram pouco.

Por meio da terceira questão, se as intervenções colaborativas motivaram a modificar as suas aulas, constatou-se que apenas um professor respondeu que não se motivou a mudar a sua prática pedagógica, tendo em vista as ações realizadas nas intervenções colaborativas; e um professor não respondeu ao questionamento. Os demais, 11 professores, responderam que ficaram motivados a modificar as suas práticas pedagógicas vigentes. As principais razões apontadas por eles foram: a necessidade de trabalhar o tema promoção da saúde para que os alunos possam modificar seus hábitos; as reflexões e conversas mostraram a importância do desenvolvimento desse tema nas aulas; e as intervenções colaborativas motivaram a trabalhar a proposta de projetos com os alunos. Como se pode observar em algumas respostas do questionário:

"Percebi a importância e a necessidade de trabalhar esses temas com meus alunos." (Professor C)

"O principal motivo é a importância da promoção da saúde na juventude e a necessidade de reavaliação de hábitos.” (Professor F)

"Essas intervenções me motivaram muito, estou até tentando melhorar a minha alimentação e praticar atividades físicas.” (Professor D)

"As intervenções causaram motivação em desenvolver um projeto com meus alunos. As aulas foram modificadas para aplicação da proposta. E no decorrer do próximo ano serão planejados novos projetos." (Professor G)

As respostas evidenciam que a maioria dos professores se sentiu motivada a modificar suas práticas pedagógicas. Notou-se, ainda, através da observação 
participante e das anotações do diário de campo, que, mediante as intervenções colaborativas, os professores se tornaram capazes de problematizar, analisar e compreender o contexto dos alunos, bem como de refletir sobre suas práticas pedagógicas, de produzir significado e conhecimento que lhes possibilitaram orientar o processo de transformação de algumas práticas escolares.

A quarta e última questão inquiriu se os professores aplicaram alguma atividade didática em suas aulas relacionada à promoção da saúde. Dos 13 professores, constatou-se que um professor não realizou nenhuma atividade; e um professor não respondeu ao questionamento. Os demais professores responderam que realizaram atividades relacionadas ao tema. Estas, para melhor análise e discussão, foram categorizadas e quantificadas, por similaridade, em quatro grupos, conforme se elenca na tabela 2 .

Tabela 2: Atividades didáticas aplicadas pelos professores

\begin{tabular}{|c|c|}
\hline Categorias & Percentuais \\
\hline Debates Reflexivos & $42 \%$ \\
\hline Dentro do Conteúdo da Disciplina & $25 \%$ \\
\hline Projetos Pedagógicos Interdisciplinares & $17 \%$ \\
\hline Trabalhos Escolares & $17 \%$ \\
\hline
\end{tabular}

Observa-se que o tema promoção da saúde foi desenvolvido principalmente através de debates reflexivos e, em menor percentual, através do conteúdo da disciplina, projetos pedagógicos interdisciplinares e trabalhos escolares. Os debates reflexivos foram compostos por explanação de textos ou vídeos ou conversa e após reflexões e debates com a turma, como se pode observar nas respostas dos professores:

\footnotetext{
"Trouxe vídeos que estavam ligados ao tema promoção da saúde. Após a apresentação realizei um debate com a turma para que eles analisassem e refletissem sobre o mesmo." (Professor C)

"Apliquei uma pirâmide alimentar com questões objetivas para os alunos debaterem e interagirem entre si." (Professor D)
}

Os resultados e os relatos dos professores evidenciam que a abordagem do tema promoção da saúde, através do desenvolvimento de debates reflexivos e projetos pedagógicos interdisciplinares, estava centrada na análise, avaliação e reflexão de fontes de informações por parte dos alunos. Observou-se, assim, que $59 \%$ dos professores desenvolveram o tema através de debates reflexivos ou por projetos pedagógicos, dos quais os alunos passaram a participar de forma ativa, dessa maneira, aproximando-se do papel que lhes compete em uma concepção crítica de ensino-aprendizagem, o de protagonista de sua aprendizagem. 
Verificou-se, ainda, que 41\% dos professores, após as intervenções colaborativas, pouco mudaram suas práticas pedagógicas, que eram desenvolvidas ainda conforme o conteúdo da disciplina ou por meio de trabalhos escolares, e, segundo os quais, o professor é o principal transmissor do conhecimento. O principal obstáculo, apontado pelos professores, registrado no diário de campo e já abordado na discussão da quinta intervenção, revelaram-se as rotinas pedagógicas exigidas pelo sistema de ensino.

No entanto, os resultados assinalam que a maioria dos professores, de uma forma ou de outra, conseguiu transpor os obstáculos, demonstrando, assim, como coloca Mendes (2007), que a pesquisa colaborativa tem sido um mecanismo utilizado para vencer barreiras presentes na escola. Ao investigar a prática, interpretando-a e buscando elementos para ressignificá-la, novos saberes se constituem, ampliando-se as perspectivas de análise dessa prática, bem como das crenças, valores e saberes que a sustentam. Essa renovação de entendimento pode resultar em mudanças nas atitudes dos professores, o que contribui tanto para a melhoria do ensino quanto para o desenvolvimento da autonomia dos mesmos em seu fazer pedagógico.

\section{CONSIDERAÇÕES FINAIS}

A partir das análises e discussões dos resultados do presente estudo, constatou-se que as intervenções colaborativas no ambiente escolar, com o uso do tema da promoção da saúde, através de uma pesquisa-ação colaborativa, desenvolveram mais mudanças cognitivas e motivacionais nos professores do que nas suas práticas docentes.

Alguns dos professores demonstraram dificuldades em modificar suas práticas docentes provavelmente por estarem muito atrelados às rotinas pedagógicas exigidas pelo sistema de ensino. No entanto o estudo revelou que os professores estão abertos a modificar seus conceitos e concepções.

Nesse sentido, intervenções colaborativas no ambiente escolar, alicerçadas em uma reflexão na prática e sobre a prática pedagógica de temas relacionados ao contexto dos alunos e da escola, podem trazer resultados satisfatórios na melhoria do ensino. Mas não é possível encarar como uma ação "milagrosa" a todos os problemas enfrentados pela escola, e sim como uma possibilidade de boas experiências de autoformação para os professores e educativas para os alunos.

Ressalta-se que as transformações nas práticas docentes dos professores levam tempo para serem construídas e reconstruídas, pois o processo de formação docente é complexo e sempre inacabado. O que exige, assim, para obtenção de maior qualidade do ensino, continuidade e novas intervenções colaborativas para que, à medida que os professores se percebam como capazes de analisar, refletir e alterar suas práticas, fortaleçam-se como pessoas e como profissionais. 
Por fim, esperamos que este estudo contribua para a área de ensino, principalmente para o ensino de ciências, uma vez que possibilita um redimensionamento no ensino, a fim de que se torne mais próximo da construção do conhecimento científico. Assim será possível superar os obstáculos de um ensino predominantemente memorístico, capaz de ultrapassar as barreiras impostas pela burocracia da organização do trabalho pedagógico, urgente para que o contexto historicamente construído possa renovar-se e realmente contribuir na educação científica.

\section{NOTA}

${ }^{1}$ Phillip Vilanova Ilha participou de todas as etapas da produção do artigo e foi responsável pela versão final. Ana Paula Santos de Lima e Daniela Sastre Rossi participaram da concepção, coleta de dados, análise e interpretação dos dados e aprovação da versão final. Félix Alexandre Antunes Soares participou da concepção, redação, revisão crítica e intelectual do artigo e aprovação da versão final.

\section{REFERENCIAS}

ALARCÃO, I. Reflexão crítica sobre o pensamento de D. Schon e os programas de formação de professores. In: ALARCÃO, I. Formação reflexiva de professores (estratégias de supervisão). Porto: Porto Editora, 1991.

ANDRADE, M. I. Educação para a saúde - Guia para professores e educadores. Lisboa: Texto, 1995.

ARAÚJO, U. F. de. Temas transversais e a estratégia de projetos. São Paulo: Moderna, 2003.

ASSIS, S. S. de; BORGES, J. N.; PAPOULA, N. da R. P. R.; SANTIAGO, C. M. da S.; TEIXEIRA, G. A. P. B. Educação em saúde - proposta de utilização de um modelo no ensino de ciências. REMPEC - Ensino, Saúde e Ambiente, Niterói, v.3 n.2, p. 108-120, agosto, 2010.

BERBEL, N. A. N.; GAMBOA, S. A. A metodologia da problematização com o Arco de Maguerez. Revista Filosofia e Educaşão, Campinas, v.3, n.2, 2011.

BARDIN, L. Análise de conteúdo. São Paulo: Edições 70, 2011.

BERTIN, R. L.; MALKOWSKI, J.; ZUTTER, L. C. I.; ULBRICH, A. Z. Estado Nutricional, hábitos alimentares e conhecimentos de nutrição em escolares. Rev. Paulista de Pediatria, São Paulo, v.28, n.3, p.3003-8, 2010.

BRASIL, Ministério do Planejamento Orçamento e Gestão; Ministério da Saúde; Instituto Brasileiro de Geografia e Estatística-IBGE. Pesquisa Nacional de saúde do escolar. Rio de Janeiro, 2009.

BRASIL. Ministério da Saúde. As cartas da promoşão da saúde. Brasília-DF, 2002.

BRASIL. Secretaria de Educação Fundamental. Parâmetros Curriculares Nacionais. Brasília: MEC / SEF, 1998.

CACHAPUZ, A. F. Do que temos, do que podemos ter e temos direito a ter na formação de professores: em defesa de uma formação em contexto. In: RAQUEL, L. L. B. (Org.). Formação de educadores: desafios e perspectivas. São Paulo: Editora Unesp, 2003.

FREIRE, P. Pedagogia do oprimido. 50. Ed. Rio de Janeiro, Paz e Terra, 2011.

GARRIDO, E.; PIMENTA, S. G.; MOURA, M. O. A pesquisa colaborativa na escola como abordagem facilitadora para o desenvolvimento da profissão do professor. 
In: Alda Marin. (Org.). Educação continuada: reflexões, alternativas. Campinas: Papirus, 2000, p. 89-112.

MARIN, A. J. (Org.). Educação continuada: reflexões, alternativas. Campinas, SP: Papirus, 2000.

IBIAPINA, I. M. L M. Pesquisa colaborativa: investigação, formação e produção de conhecimentos. Brasília: Líber Livro Editora, 2008.

LIBÂNEO, J. C. As teorias pedagógicas modernas revisitadas pelo debate contemporâneo na educação. In: LIBÂNEO, J. C.; SANTOS, A. (Orgs.). Educação na era do conbecimento em rede e transdisciplinaridade. Campinas: Alínea, 2005.

LOMÔNACO, A. F. S. Concepções de Saúde e Cotidiano Escolar - O Viés do Saber e da Prática. In: REUNIÃO ANUAL DA ASSOCIAÇÃO NACIONAL DE PÓSGRADUAÇÃO E PESQUISA EM EDUCAÇÃO, 27., 2004. Caxambu/MG. Anais... Caxambu: ANPEd, 2004. Disponível em: <http://27reuniao.anped.org.br/gt06/t063 .pdf>. Acesso em: 01 jul. 2012.

MAINARDI, N. Educação em Saúde: Problema ou solução?. Orientador: Isabel Maria Teixeira Bicudo Pereira. 2010. 135f. Tese (Doutorado em Saúde Pública) - Faculdade de Saúde Pública, Universidade de São Paulo, São Paulo, 2010.

MENDES, M. R. M. Pesquisa colaborativa e comunidade de aprendizagem: possíveis caminhos para a formação continuada. 2007. 168f. Dissertação (Mestrado em Ensino de Ciências), Programa de pós-graduação em Ensino de Ciências, Universidade de Brasília, Brasília, 2007.

MIZUKAMI, M. G. N. A pesquisa sobre formação de professores: metodologias alternativas. In: BARBOSA, R. L. L (Org.). Formação de educadores: desafios e perspectivas. São Paulo: Editora Unesp, 2003.

MORAN, J. M.; MASETTO, M. T.; BEHRENS, M. A. Novas tecnologias e mediação pedagógica. Campinas: Papirus Editora, 12 ed. 2006.

NÓVOA, A. Professor se forma na escola. Nova Escola, São Paulo. Editora Abril, 2001.

PEREIRA, M. G, et al. Aprender a escolher: promoção da saúde no contexto escolar. Psicologia: teoria, investigação e prática, São Paulo, v.5. n.1, p. 147-158, 2000.

PIMENTA, S. G.; GARRIDO, E.; MOURA, M. O. Pesquisa colaborativa na escola facilitando o desenvolvimento profissional de professores. In: REUNIÃO ANUAL DA ASSOCIAÇÃO NACIONAL DE PÓS-GRADUAÇÃO E PESQUISA EM EDUCAÇÃO, 24., 2001. São Paulo. Anais... São Paulo: USP, 2001. Disponível em: $<$ http://www.cefetes.br/gwadocpub/Pos-Graduacao/Especializa $\%$ C3\%A7\%C3\%A3 O $\% 20$ em $\% 20$ educa $\%$ C3\%A7\%C3\%A3o\%20EJA/Publica $\%$ C3\%A7\%C3\%B5es/anped $2001 /$ textos/sesselma.PDF>. Acesso em: 10 jul. 2012.

PRADO, M. Pedagogia de Projetos. In: BRASIL. Ministério da Educação. Pedagogia de Projetos e Integração de Mídias. MEC: Brasília, 2003. p.1-14.

RAMOS, P.; STRUCHINER, M. Concepções de educação em pesquisas sobre materiais informatizados para o ensino de ciências e de saúde. Ciência e Educação. São Paulo, 15 (3): 13-27, 2009.

RIBEIRO, G. F. P. A importância do professor pesquisador. 2010. 14f. Monografia (Especialização em Docência na Educação Superior) - Faculdade de Educação, Universidade Federal do Triângulo Mineiro, Uberaba/MG, 2010.

SÍCOLI, J. L; NASCIMENTO, P. R. do. Promoção de saúde: concepções, princípios e operacionalização. Revista Interface, Botucatu, v.7, n.12, p.101-22, fev - 2003.

SISTEMA DE VIGILÂNCIA ALIMENTAR E NUTRICIONAL. Normas técnicas: Classificação do estado nutricional em crianças. Brasília, 2006. 4 p. Disponível em: <http://189.28.128.100/ nutricao/docs/geral/sisvan_norma_tecnica_criancas.pdf>. Acesso em: 16 jul. 2011.

THIOLLENT, M. Metodologia da pesquisa-ação - 18. Ed. - São Paulo: Cortez, 2011. 
TRICHES, R. M.; GIUGLIANI, E. R. J. Obesidade, práticas alimentares e conhecimentos de nutrição em escolares. Revista Saúde Pública, São Paulo, v.39, n.4, p.541-547, 2005.

ZEICHNER, K. Para além da divisão entre professor, pesquisador e pesquisador acadêmico. In: GERALDI, C. M. G.; FIORENTI, D.; PEREIRA, E. M. de A. Cartografia do trabalho docente: Campinas, SP: Mercado de Letras, 1998.

Data Recebimento: 26/05/2013

Data Aprovação: 13/08/2014

Data Versão Final: 20/09/2014

Contato:

Phillip Vilanova Ilha

Grupo de Estudos em Nutrição, Saúde e Qualidade de Vida

Universidade Federal de Santa Maria - Centro de Ciências Naturais e Exatas (CCNE) - Prédio 13B. Av.

Roraima, 1000- Campus Universitário - Bairro Camobi

Santa Maria-RS - Brasil - CEP 97105-900. Email: phillip_ilha@hotmail.com 
